\title{
Simultaneous bioelectricity generation, desalination, organics degradation, and nitrogen removal in air-cathode microbial desalination cells
}

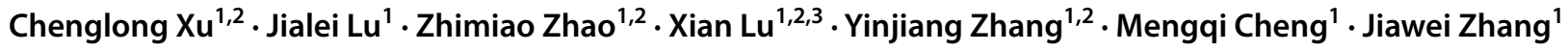

Received: 29 October 2019 / Accepted: 3 January 2020 / Published online: 14 January 2020

(c) Springer Nature Switzerland AG 2020

\begin{abstract}
In this study, a three-chamber air-cathode microbial desalination cell (AMDC) was constructed using activated sludge as the inoculating microbial source and carbon cloth as the electrode. The simultaneous bioelectricity generation, desalination, degradation of organic compounds, and nitrogen removal in the AMDC having different electrode spacings $(16,12$, and $8 \mathrm{~cm})$ provided an insight into the microbial community. The experimental results showed that with a gradual decrease in the electrode spacing, electricity production and desalination performance first increased and then decreased. While AMDC1 with $16 \mathrm{~cm}$ electrode spacing became active faster than other cells and reached a peak voltage of $598 \mathrm{mV}$ on the tenth day, AMDC2 with $12 \mathrm{~cm}$ electrode spacing showed the best start-up performance with a maximum output voltage of $645 \mathrm{mV}$, maximum power density of $214.7 \mathrm{~mW} / \mathrm{m}^{3}$, and minimum resistance of $516.9 \Omega$. AMDC3 with $8 \mathrm{~cm}$ electrode spacing reached a peak voltage of $598 \mathrm{mV}$, which was between those of AMDC1 and AMDC2. The three AMDCs were run until the end of the cycle, and there was no significant difference in their ammonium removal rate and chemical oxygen demand. For AMDC1-3, the desalination rates were $84.86 \%, 87.71 \%$, and $83.43 \%$, and the Coulomb efficiencies were $17.29 \%, 18.60 \%$, and $17.95 \%$, respectively. Further, scanning electron microscopy showed that a large number of microorganisms could attach to the surface of the anode carbon cloth electrode; 16S rRNA sequencing showed that the typical electrogenic microbial communities were Bacillus (11.6\%) and Arcobacter (9.6\%). As the poor performance of the AMDC was primarily due to a lack of electrogenic microorganisms in the active function of the anode chamber, screening the functional microorganisms provided a reference for optimizing and amplifying the application of microbial desalination cells in practical research.
\end{abstract}

Keywords Air-cathode microbial desalination cell · Electrode spacing · Desalination · Organics degradation · Nitrogen removal $\cdot$ Microbial community

\section{Introduction}

Water is crucial for human survival, and water shortage and pollution problems have increased significantly worldwide in recent years [1,2]. The total volume of water on the Earth is $\sim 1.386$ billion cubic kilometers. However, freshwater accounts for only $2.53 \%$ of the total water reserves. Freshwater resources available for human use (including rivers, freshwater lakes, shallow groundwater, etc.) merely account for $0.3 \%$ of the total freshwater reserves. Therefore, desalination and wastewater treatment are effective ways to increase the amount of water

$\triangle$ Xian Lu, xlu@shou.edu.cn; $\square$ Yinjiang Zhang, yjzhang@shou.edu.cn | ${ }^{1}$ College of Marine Ecology and Environment, Shanghai Ocean University, Shanghai 201306, China. ${ }^{2}$ Water Environment and Ecology Engineering Research Center of Shanghai Institution of Higher Education, Shanghai 201306, China. ${ }^{3}$ State Key Laboratory of Pollution Control and Resources Reuse, College of Environmental Science and Engineering, Tongji University, Shanghai 200092, China. 
resources. The nexus of energy, water, and environment is crucial for future seawater desalination sustainability, research in desalination methods contributing to reduce specific energy consumption and protect the environment [3]. Several seawater desalination technologies, such as reverse osmosis (RO) [4], multi-cascade evaporators [5], multi-stage flashing (MSF) [6], multi-effect distillation (MED) [7], seawater thermocline-driven MED (ST-MED) [8], multi-effect distillation, and an adsorption cycle (MED-AD) $[9,10]$, have been reported in the literature. The recent hybridization trend of different desalination technologies has been to overcome the individual technological limitations. The economics of desalination technologies has been improving continuously owing to the expansion of the desalination market. Consequently, high-efficiency and low-consumption methods of desalination and wastewater treatment, and improvements of the performance ratios of these technologies have become the focus of research and development in the field of environmental engineering [11-14].

Microbial desalination cells (MDCs) are a new type of technology developed from microbial fuel cells (MFCs) for the first time at Tsinghua University for power production, desalination and wastewater treatment. The concept of operation of MDCs is similar to water electrodialysis, but the MDC is a device that uses bacteria as a catalyst to transform the chemical energy that exists in wastewater into electricity through electrochemical reactions. MDCs employ an additional chamber that contains salty water between the anode and cathode chambers of the MFCs. lon exchange membranes separate the three chambers and permit the migration of salt ions to achieve desalination [15-17]. After the invention of MDCs by Cao et al. [18], researchers have developed recirculation microbial desalination cells (rMDCs) that avoid $\mathrm{pH}$ imbalance and accelerate bacterial respiration to increase the power of MDCs and achieve efficient desalination [19]. Desalination and treatment of chromium-containing wastewater have been achieved using a new three-chamber MDC [20]. Stacked resin-packed microbial desalination cells (SR-MDCs) filled with mixed ion exchange resins have also been implemented for secondary desalination of domestic sewage [21]. Microbial capacity desalination cells with the capacity to regenerate through exchange of the connection between the electrode and activated carbon cloth assemblies have been reported [22]. MDCs show great potential in bioelectricity generation, wastewater purification, and desalination owing to their excellent stability. They have been widely studied because of advantageous attributes such as low cost, good stability, wastewater treatment capacity, and desalination ability. However, most studies have so far only been conducted with laboratory-scale designs, and there are no reports of their practical applications.

Studies have shown that electrode spacing is an important parameter that can influence the performance of MFCs owing to its role in determining the internal resistance of the cell, electrode potential, power production, extent of organic removal, conductivity, etc. For further study on scale-up devices and broadening the practical application of MDCs, it is worth investigating their performance and efficiency with different electrode spacings.

Based on the traditional MDCs, in this experiment, a three-chamber air-cathode microbial desalination cells (AMDC) was designed and initiated. The effect of different electrode spacings $(16,12$, and $8 \mathrm{~cm})$ on the performance of the AMDC was investigated by using carbon cloth as the electrode material. Meanwhile, salt, organics, and nitrogen removal efficiency of the AMDC were evaluated, and 16S rRNA sequence was used to assess the structure and function of microbial community. The long-term operation stability of the AMDC was also examined in terms of current output, power generation, columbic efficiency (CE), internal resistance, and polarization to further evaluate their performance.

\section{Materials and methods}

\subsection{Experimental materials and AMDC construction}

The three chambers of the AMDC, namely anode, desalination, and cathode, were constructed using an acrylic cube cut into $6 \mathrm{~cm}, 10 \mathrm{~cm}$, and $20 \mathrm{~cm}$ pieces, respectively, and separated with ion exchange membranes. The three chambers had a total working volume of $3.6 \mathrm{~L}$ (Fig. 1). Both the anion exchange membrane (AEM, AMI-Grion0011V; Lvhe Co., Ltd., China) and cation exchange membrane (CEM, CMI-Grion0011V; Lvhe Co., Ltd., China) exchange membranes had a cross-sectional area of $60 \mathrm{~cm}^{2}$. Both AEM and CEM were prepared as described in a previous study [23], and in accordance with the manufacturer's instructions, the membranes were left in $5 \% \mathrm{NaCl}$ solution for $48 \mathrm{~h}$ to allow hydration and expansion before installation. Both the anode and cathode were made from carbon cloths $(6 \mathrm{~cm} \times 12 \mathrm{~cm}, \mathrm{~B} 1 \mathrm{~B}, \mathrm{E}-\mathrm{Tech}, \mathrm{USA})$, and pre-treated with $15 \% \mathrm{v} / \mathrm{v}$ acetone solution for $24 \mathrm{~h}$ before use to remove the grease stain on the machined surface. The electrodes were immersed in distilled water, and before the experiment, rinsed with deionized water and then placed in an oven to dry [24]. A closed-circuit was set up by connecting a titanium wire coupled with an external resistance $(1000 \Omega)$. Three groups of AMDCs with different electrode spacings $(16,12$, and $8 \mathrm{~cm})$ were designed as AMDC1, 
Fig. 1 Schematic diagram of the air-cathode microbial desalination cells

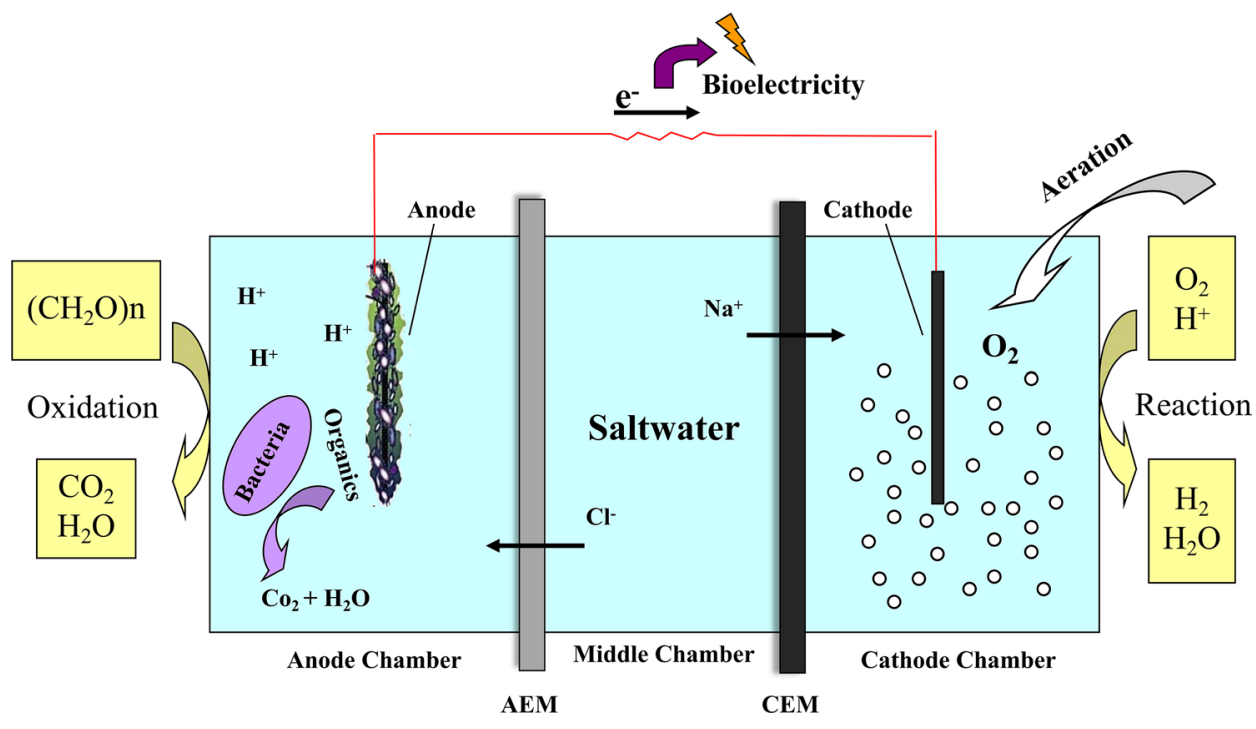

$A M D C 2$, and AMDC3, respectively. The reactor was operated intermittently.

\subsection{System inoculation and culture solution}

To further reduce the start-up period and operating costs of the AMDC, the cathode chamber was directly inoculated with aerobic sludge collected from second sedimentation in a local wastewater treatment plant (Lingang New City, Shanghai). The ratio of aerobic sludge and nutrient solution was 1:1, and it was sealed and subjected to constant temperature $\left(30^{\circ} \mathrm{C}\right)$ oscillation in a water bath for a few days to obtain anaerobic sludge as an anode chamber inoculation of microorganisms [25]. To ensure an adequate electron donor, the anode chamber was fed with glucose nutrient medium as the fuel containing $\mathrm{C}_{6} \mathrm{H}_{12} \mathrm{O}_{6}(0.56 \mathrm{~g} / \mathrm{L})$, $\mathrm{KH}_{2} \mathrm{PO}_{4}(4.40 \mathrm{~g} / \mathrm{L}), \mathrm{K}_{2} \mathrm{HPO}_{4}(3.40 \mathrm{~g} / \mathrm{L})$, and $\mathrm{NH}_{4} \mathrm{Cl}(0.32 \mathrm{~g} / \mathrm{L})$. The anode chamber was stirred using a magnetic stirrer (40-50 rpm) to mix the components thoroughly. The cathode chamber was treated with sodium bicarbonate as the nutrient substance containing $\mathrm{KH}_{2} \mathrm{PO}_{4}(4.40 \mathrm{~g} / \mathrm{L})$, $\mathrm{K}_{2} \mathrm{HPO}_{4}(3.40 \mathrm{~g} / \mathrm{L}), \mathrm{NH}_{4} \mathrm{Cl}(0.32 \mathrm{~g} / \mathrm{L})$, and $\mathrm{NaHCO}_{3}(1.92 \mathrm{~g} / \mathrm{L})$. Continuous aeration was achieved by an aerating pump to increase dissolved oxygen (DO), and the cathodic DO concentration was controlled at greater than or equal to $6.0 \mathrm{mg} / \mathrm{L}$ by adjusting the flow aerator. Further, $12.5 \mathrm{~g} / \mathrm{L}$ of trace metal and $5 \mathrm{~g} / \mathrm{L}$ of vitamin solutions were separately added to both chambers $[21,26]$. The desalination chamber was filled with artificial salt water containing $35 \mathrm{~g} / \mathrm{L}$ of $\mathrm{NaCl}$ solution. After inoculation, the anolyte, catholyte, and salt solution were not changed until the voltage reached $100 \mathrm{mV}$. During the start-up and operational stages, the cathode chamber was refilled with new solution every $48 \mathrm{~h}$.

\subsection{Measurements and analysis}

To assess the performance of the AMDC, conventional water quality indicators such as chemical oxygen demand (COD), ammonia, and nitrate nitrogen were determined and referenced to the standard methods [27]. The solution $\mathrm{pH}$ and $\mathrm{NaCl}$ concentration were monitored using a multi-parameter water quality analyzer (HQ40; Hach, USA).

The electrochemical characteristics of the AMDC were studied as follows. Cell voltage was recorded every minute by an 8-channel data acquisition system (RTKINS Co., Ltd., Wuhan, China) connected to a computer, and the averages were calculated every hour. The steady state reading was recorded at each resistance value. Power generation, current density $\left(\mathrm{A} / \mathrm{m}^{3}\right)$, and power density $\left(\mathrm{mW} / \mathrm{m}^{3}\right)$ were calculated and analyzed by the net total working volume. The polarization curves were obtained by varying the external resistance from 1000 to $50 \Omega$ as described by Qu et al. [28]. The cell internal resistance was obtained from the polarization curve as described by Logan et al. [29]. Finally, the coulombic efficiency (CE) was used to characterize the electrical capacity of the anode microorganisms.

\subsection{Scanning electron microscopy and microbial community structure analysis}

At the end of the experiment, the anode carbon cloth electrodes of the AMDC with the best effect were immediately stored at $-20^{\circ} \mathrm{C}$ after being taken out from the chambers. The structures of the carbon cloths and microbial community were observed and evaluated using scanning electron microscopy (SEM). The primer sets used were $338 \mathrm{~F}$ (ACTCCTACGGGAGGCAGCA) and 806R (GGACTACHVGGG TWTCTAATAT). The V3-V4 regions of the bacterial 16S rRNA gene were analyzed on an Illumina MiSeq platform 
(Personal Biotechnology Co., Ltd., Shanghai, China) to identify the dominant electrochemically active bacteria [30].

\section{Results and discussion}

\subsection{Bioelectricity generation characteristics of the AMDC}

\subsubsection{Start-up of the AMDC under diverse electrode spacing}

The reactor was operated intermittently at a temperature of $25 \pm 1^{\circ} \mathrm{C}$. The cathode used oxygen as an electron donor, the desalination chamber was filled with $35 \mathrm{~g} / \mathrm{L}$ of $\mathrm{NaCl}$ solution, and the anode chamber was fed with glucose nutrient medium as a fuel. The dynamic changes in the output voltage with time during the operation of the AMDC are shown in Fig. 2. The output voltage exceeded $600 \mathrm{mV}$ for two consecutive periods and tended to be stable. The reactor start-up phase was complete after 30 days of culture, and the maximum voltage was $\sim 645 \mathrm{mV}$, which is similar to the voltage generated by traditional MFCs [31].

The voltage was low at the beginning, likely because there was an insufficient amount of sludge inoculation, which led to low accumulation of electrogenic microorganisms on the anode surface. Consequently, the inoculated microorganisms needed to adapt to the new environment and showed slow metabolism. As a result, the output voltage of the three AMDCs showed considerable fluctuations. As domesticated microorganisms gradually adapted to the new environment, constant absorption of the substrate nutrients accelerated their growth and metabolism led to a rapid increase in the voltage [32]. The output voltages of the three AMDCs reached a peak on and around day 10,12 , and 12 , respectively, and the microbial adhesion reached the highest level and remained stable. The reactor entered a stable period and continued to operate for 5 days. On day 17, owing to nutrient consumption and accumulation of metabolites in the reactor, microbial growth was restricted and the output voltage gradually decreased. On day 20 , the initial period in the second cycle of substrate solution replacement was shorter than in the first cycle. A possible reason is that the metabolism of electricity-producing microorganisms accelerated and the substrate nutrition was consumed rapidly, which is consistent with the change in the COD.

As shown in Fig. 2, the maximum voltages of AMDC1-3 were 598,645 , and $610 \mathrm{mV}$, respectively. Under the same conditions of anode electrode materials, AMDC2, with its electrode spacing of $12 \mathrm{~cm}$, showed the best effect, followed by AMDC3 with its electrode spacing of $8 \mathrm{~cm}$, and the AMDC1 with the electrode spacing of $16 \mathrm{~cm}$ has the worst effect. As the electrode spacing decreased, the maximum voltage first increased and then declined. The reason may be that the different electrode spacing changed the internal resistance of the AMDC, which is consistent with the change in power density.

The anode chamber used glucose as the sole carbon source while the cathode chamber used oxygen as the sole electron donor. The changes in $\mathrm{COD}$ and $\mathrm{NaCl}$ concentration in the AMDC open- and closed-circuit systems are shown in Fig. 3.
Fig. 2 Output voltage during the start-up period (arrow indicates anolyte replacement)

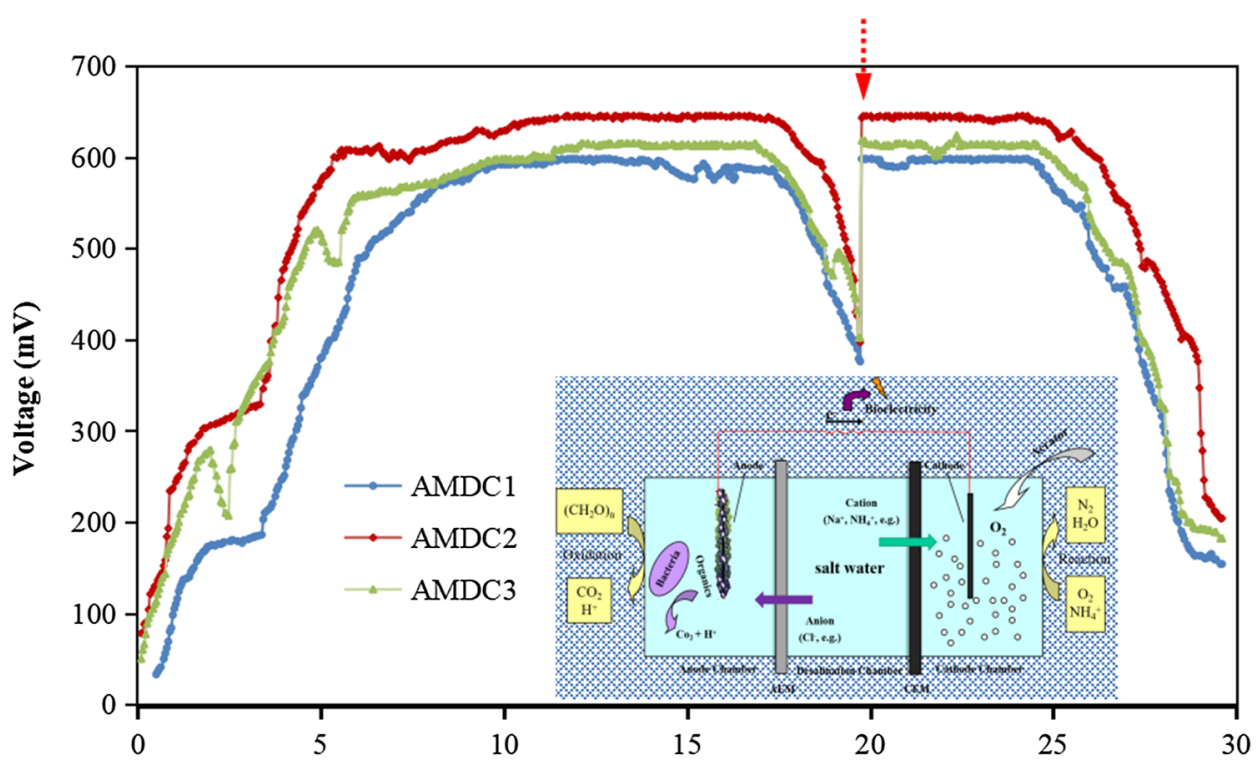

Time (d) 

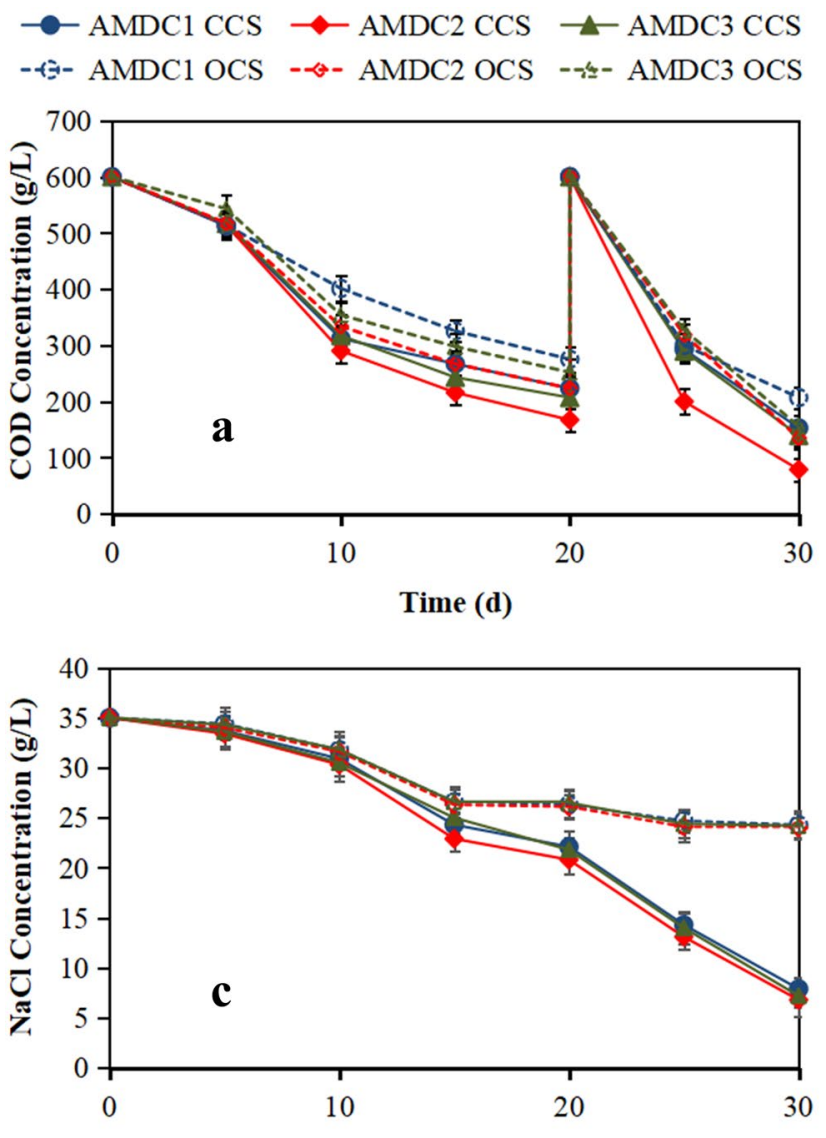

Time (d)
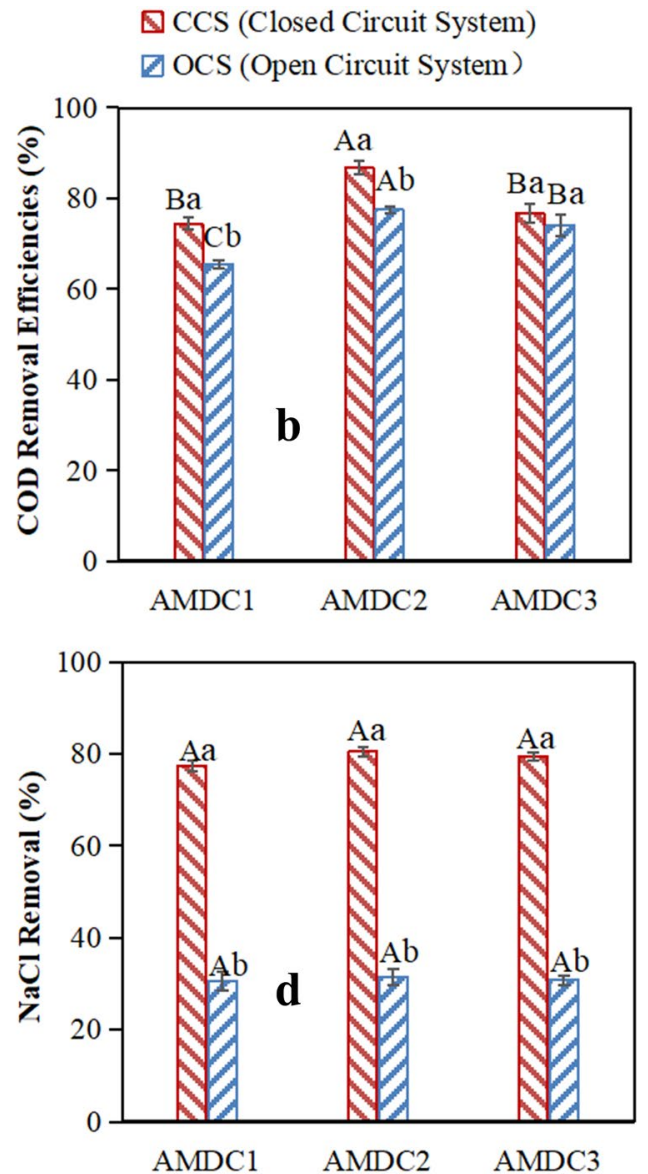

Fig. 3 Changes in $\mathrm{COD}(\mathbf{a}), \mathrm{NaCl}$ concentration (c), $\mathrm{COD}$ removal efficiency (b), and $\mathrm{NaCl}$ removal efficiency (d) for the open-circuit system (OCS) and closed-circuit system (CCS) under different electrode spacings. In $\mathbf{b}$, d, different uppercase letters indicate signifi-

The difference of the COD degradation rates in OCS and CCS was not significant $(p>0.05)$. The anode microorganisms in the three AMDCs had the same effect on the degradation of organic matter, and the results of inoculation of the same kind of sludge were consistent. Furthermore, there was no significant effect on the COD degradation rate between the OCS and CCS on changing the electrode spacings. Voltage output under the closed-circuit system indicated that the anode microorganisms oxidized organic matter to produce electron transfer to the cathode, which constituted a closed loop. Under the action of an electric field, the salt ions in the desalination chamber were pushed to migrate to both ends, which significantly promoted the $\mathrm{NaCl}$ concentration change caused by single concentration differential dialysis in the open-circuit system $[33,34]$. There was a significant effect of promoting the change in $\mathrm{NaCl}$ concentration in the CCS concentration was significantly different $(p<0.01)$. Under identical system conditions, the difference in $\mathrm{NaCl}$ concentration in the cant differences between the same system at different electrode spacings $(p<0.05)$. Different lowercase letters indicate significant differences between the different systems at the same electrode spacing $(p<0.05)$

three AMDCs was not significant $(p>0.05)$. In summary, the AMDC with an electrode spacing of $12 \mathrm{~cm}$ had a higher COD degradation rate and changes in $\mathrm{NaCl}$ concentration than other AMDC.

\subsubsection{Power density curves and polarization curves of the AMDCs}

In the CCS, the current density and volume power density were calculated from the effective volume of the reactor, and the polarization curves were determined by the steady state discharge method [33]. During the stable power production stage of the experiment, polarization measurements were made using a variable resistor box, and the external resistance was reduced stepwise from $1000 \Omega$ to $50 \Omega$ (the external resistances were, respectively, $1000,500,300,200,100,50 \Omega)$. The power density curves and polarization curves are shown in Fig. 4. The maximum power densities of the three AMDCs were 184.0, 214.7, and 


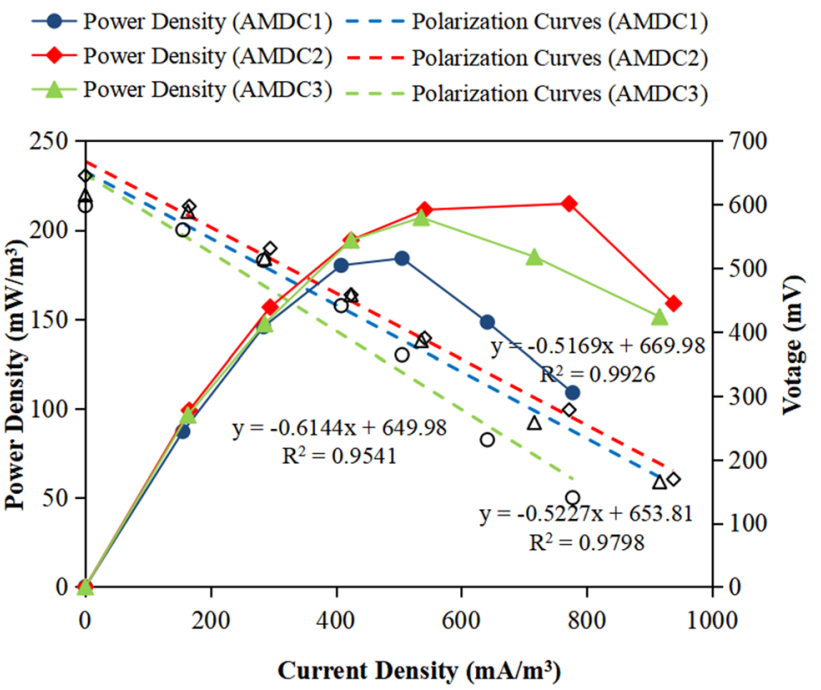

Fig. 4 Power density curves and polarization curves of the AMDC under diverse electrode spacing

$206.9 \mathrm{~mW} / \mathrm{m}^{3}$, respectively, which was slightly lower than that of the conventional reactor. This may be attributed to the lack of electricity-generating microorganisms in the inoculation sludge function, or the slow metabolism of microorganisms with insufficient substrate nutrients that resulted in the poor electricity-generating effect [26]. In addition, the reactor internal resistance was large and the reduction rate of the cathode oxygen electron donor on the electrode was slow, which limited the overall power output of the reactor that resulted in a low power density.

The $\mathrm{NaCl}$ concentration in the desalination chamber gradually decreased with the operation of the reactor, and the conductivity of the low-concentration solution declined, which increased the internal resistance of the AMDC. At a certain stage, the power density of the three
AMDCs showed a decreasing trend. Thus, decreasing the electrode spacing effectively reduced the internal resistance of the reactor and increased the output power. In the CCS, when the electrode spacing was changed from 16 to $8 \mathrm{~cm}$, the power density increased from 184.0 to $214.7 \mathrm{~mW} / \mathrm{m}^{3}$, and then decreased to $206.9 \mathrm{~mW} / \mathrm{m}^{3}$, and the internal resistance of the three AMDCs was 614.4, 516.9 , and $522.7 \Omega$, respectively. The results showed that reducing the electrode spacing effectively reduced the resistance to ion migration in solution, which was beneficial to the degradation of organic matter by microorganisms, and sped up the mass transfer of organic matter and products, thus reducing the resistance of mass transfer in the reactor and increasing the output power of the reactor. In conclusion, the three-chamber AMDC had a good start. With the same electrode materials, the AMDC with an air-cathode spacing of $12 \mathrm{~cm}$ showed the best starting effect.

\subsection{Analysis of desalination, organics degradation, and nitrogen removal}

\subsubsection{Organics and nitrogen removal efficiency}

After start-up, the anode substrate of the AMDC was updated and the operation began. The three AMDCs lasted 12.5 days from the end of the cycle, and the removal effect of major pollutants is shown in Table 1. During the operation of the three AMDCs, the organic matter in the substrate was decomposed by the catalytic activity of the anaerobic microorganisms. As a result, the COD concentration of the anode substrate solution decreased. As calculated in Table 1, the COD degradation rates of the anode substrate solution of the three AMDCs were 69.03, 71.69, and $69.79 \%$, respectively, i.e., not significantly different
Table 1 Influent and effluent concentrations of the AMDC with different electrode spacings

\begin{tabular}{lllllll}
\hline Class & Location & Mode & $\mathrm{pH}$ & $\mathrm{COD}(\mathrm{mg} / \mathrm{L})$ & Ammonium $(\mathrm{mg} / \mathrm{L})$ & $\begin{array}{l}\text { Nitrate } \\
\text { nitrogen } \\
\text { (mg/L) }\end{array}$ \\
\hline AMDC1 & Anode chamber & Influent & 6.67 & 600.00 & 42.72 & 2.39 \\
& & Effluent & $6.04 \pm 0.10$ & $185.82 \pm 9.64$ & $11.20 \pm 1.23$ & $2.06 \pm 0.06$ \\
& Cathode chamber & Influent & 6.92 & - & 18.67 & 0.97 \\
& & Effluent & $7.51 \pm 0.15$ & - & $3.24 \pm 0.08$ & $1.24 \pm 0.04$ \\
AMDC2 & Anode chamber & Influent & 6.67 & 600.00 & 42.72 & 2.39 \\
& & Effluent & $5.87 \pm 0.19$ & $169.86 \pm 10.25$ & $10.36 \pm 1.20$ & $1.99 \pm 0.02$ \\
& \multirow{4}{*}{ Cathode chamber } & Influent & 6.92 & - & 18.67 & 0.97 \\
& & Effluent & $7.97 \pm 0.24$ & - & $2.98 \pm 0.14$ & $1.26 \pm 0.07$ \\
AMDC3 & Anode chamber & Influent & 6.67 & 600.00 & 42.72 & 2.39 \\
& & Effluent & $5.98 \pm 0.08$ & $181.26 \pm 8.50$ & $10.97 \pm 0.98$ & $2.14 \pm 0.08$ \\
& \multirow{2}{*}{ Cathode chamber } & Influent & 6.92 & - & 18.67 & 0.97 \\
& & Effluent & $7.62 \pm 0.21$ & - & $2.77 \pm 0.08$ & $1.27 \pm 0.04$ \\
\hline
\end{tabular}


$(p>0.05)$. These results indicate that microorganisms have the same catalytic ability to decompose organic matter, and the change of electrode spacing has no significant effect on microbial degradation. The reasons for this COD removal effect that may be the resistance of anode material and reaction rate of cathode. As the resistance of the anode material decreased, the removal amount of COD increased considerably, while the changes in the cathode reaction rate had little impact on the removal effect of COD.

Ammonia nitrogen $\left(\mathrm{NH}_{3}-\mathrm{N}\right)$ exists in the anode substrate solution in the form of free ammonia $\left(\mathrm{NH}_{3}\right)$ or ammonium $\left(\mathrm{NH}_{4}{ }^{+}\right)$. When the $\mathrm{pH}$ is high, it exists in the free form, and vice versa as ammonium. During the operation of the AMDC, denitrifying ammonia oxidizers under hypoxia conditions, $\mathrm{NH}_{4}{ }^{+}$was denitrified into $\mathrm{N}_{2}$, thereby reducing the $\mathrm{NH}_{4}^{+}$content in the solution. Meanwhile, with the operation of the AMDC, the $\mathrm{pH}$ of the anode chamber decreased and free ammonia escaped as a gas, which is also one of the reasons for the decreasing concentration of ammonia nitrogen in the anode chamber. The ammonium removal rates of the anode substrate solutions of the three AMDCs were $73.78,75.74$, and $74.32 \%$, respectively, with no significant difference $(p>0.05)$, which was the same as COD degradation. The ammonium removal rates of the cathode chamber of the three AMDCs were higher than that of the anode chamber, which were 82.64, 84.03 , and $85.16 \%$, respectively. This was attributed to the aeration of the cathode chamber and conversion of ammonium $\left(\mathrm{NH}_{4}^{+}\right)$into nitrate nitrogen $\left(\mathrm{NO}_{3}{ }^{-} \mathrm{N}\right)$ under aerobic conditions, which was consistent with the increase in nitrate nitrogen concentration in the cathode chamber. The results showed that the AMDC can degrade inorganic nitrogen pollutants effectively, and the change of electrode spacing had no significant effect on the degradation of inorganic nitrogen pollutants.

The initial $\mathrm{pH}$ values of the AMDC anode and cathode electrolytes were 6.67 and 6.92 , respectively. At the end of operation, $\mathrm{pH}$ values of the AMDC1-3 anode electrolytes had decreased, while those of the cathode electrolytes had increased; this variation was the most obvious for the AMDC2 reactor with an electrode spacing of $12 \mathrm{~cm}$. During the operation of the AMDC, the $\mathrm{pH}$ decreased and increased for the anolyte and catholyte, respectively, probably because the organics in the anode chamber were degraded, $\mathrm{H}^{+}$were produced, and $\mathrm{e}^{-}$were released. The $\mathrm{e}^{-}$reached the cathode through the external circuit and combined with $\mathrm{O}_{2}$ to produce $\mathrm{H}_{2} \mathrm{O}$. The $\mathrm{H}^{+}$generated in the anode chamber and $\mathrm{OH}^{-}$generated in the cathode chamber accumulated continuously, leading to a change in the $\mathrm{pH}$ value. The extremely low and high $\mathrm{pH}$ values of the anolyte and catholyte, respectively, adversely affected the reactor performance. The $\mathrm{pH}$ change in the AMDC2 reactor was the most obvious. As mentioned above, with the reduction of electrode spacing, the internal resistance of the reactor decreased, which was conducive to the decomposition of anaerobic microorganisms. Therefore, the combined effect of $\mathrm{pH}$ change and electrode spacing had no significant effect on the degradation of organics in the reactor, which is consistent with the removal effect of COD.

\subsubsection{Analysis of desalination and energy recovery efficiency}

The three AMDCs were operated until the end of the cycle, and the desalination effect under diverse electrode spacing conditions was studied (Fig. 5). The $\mathrm{NaCl}$ concentration in the three AMDCs decreased gradually with time, and the desalination efficiencies were $84.86 \%, 87.71 \%$, and $83.43 \%$, respectively. As described in Sect. 2.1 , the desalination effect of the electricity generation was affected by the electrode spacing. The AMDC with an electrode spacing of $12 \mathrm{~cm}$ showed good electrical desalination characteristics compared with the other two AMDCs. Coulomb efficiency is used to measure the ability of anode microorganisms to convert organic matter into electrical energy $[35,36]$. The calculated Coulombic efficiencies of the three AMDCs were $17.29,18.60$, and $17.95 \%$, respectively. Under the same operating conditions, the difference in the Coulombic efficiencies of the three AMDCs was significant $(p<0.05)$ on changing the electrode spacing, which showed that the utilization rate of organic matter was similar. The possible reasons for this result are the following: (1) the influence of electrode spacing on the internal resistance of the reactor; (2) the change of $\mathrm{pH}$ of the anode and cathode chamber; and (3) the loss of energy of organic

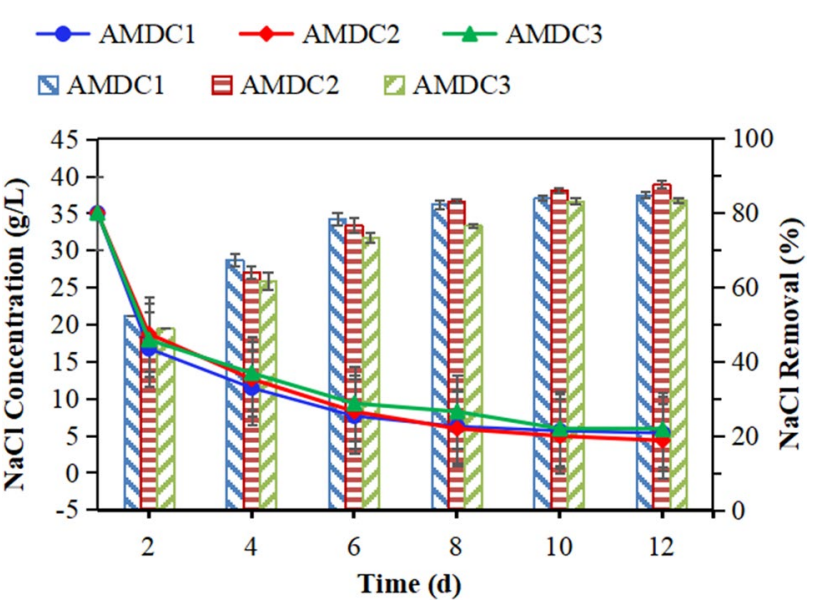

Fig. 5 Desalination rate versus time of the AMDC under diverse electrode spacing 
substrate hydrolysis, and other human factors, such as the error of current intensity measurement.

\subsection{Growth and microbial community analyses}

\subsubsection{SEM images of anode electrode of the AMDC}

To further analyze the microbial adhesion growth of the anode carbon cloth electrode on the AMDC under different electrode spacing conditions, the morphology of the carbon cloth electrode was analyzed by SEM, and the results were shown in Fig. 6. The carbon cloth electrode pre-treated by acetone immersion had a uniform surface, loose texture, and a membrane surface with a large number of voids, which were conducive to the adhesion and growth of microorganisms. After a period of operation, the three AMDCs were observed using a scanning electron microscope under $\times 250 \mathrm{SE}$ and $\times 500 \mathrm{SE}$, respectively. Microorganisms were attached to the surface of the anode electrode, effectively utilizing the void structure of the membrane surface to enable the microorganisms to degrade organic matter smoothly.

\subsubsection{Analysis of microbial community structure characteristics}

Microorganisms, as the core of the MDCs, play an important role in the biocatalytic reaction for power generation and pollutant removal. Experimental results show that the performance of the AMDC needs to be improved compared to previous studies. To further verify the hypothesis that poor performance was due to a lack of functional electricity-producing microorganisms, we conducted an in-depth study of the microbial communities. Through the $16 \mathrm{~S}$ rRNA sequencing analysis, the anode microbial community structure of the AMDC with the best electrode spacing of $12 \mathrm{~cm}$ was analyzed and divided according to $97 \%$ homology. A total of 1512 OUT classification
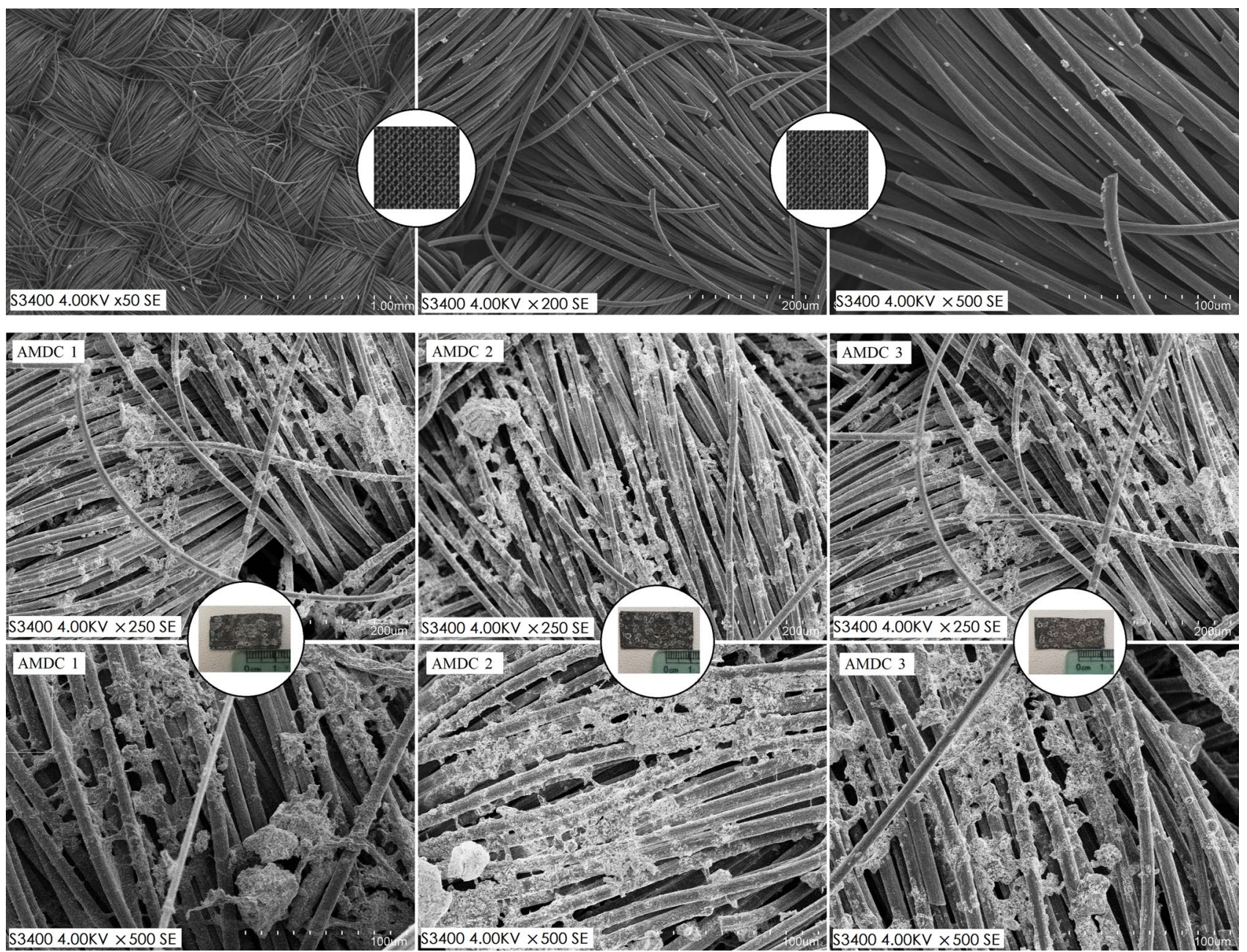

Fig. 6 SEM images of anode carbon cloth electrode of the AMDC under diverse electrode spacing

SN Applied Sciences 
operation units were obtained. The total number of Chao1, Ace, and Simpson indicators were 1621, 1733, and 0.9678, respectively, with high microbial richness and diversity, and the Shannon index was 7.5. The bands flattened out when the number of bands read was more than 10,000 , indicating that the sequencing of bands was reasonable, and it was less likely that new species would be discovered at greater sequencing depth.

The microbial community structure in the anode of the AMDC was analyzed using the Illumina MiSeq sequencing platform, and the results are shown in Fig. 7.

As shown in Fig. 7, at phylum level, the Bacteroidetes accounted for the highest proportion in the anode chamber (33.9\%), followed by Firmicutes and Proteobacteria, accounting for $30.7 \%$ and $26.1 \%$, respectively. Studies by Cabezas show that Proteobacteria and Bacteroidetes contain a variety of electrogenic microorganisms [37, 38]. Proteobacteria were enriched in the MDCs, and Bacteroidetes could metabolize some easily degraded organic matter and improve the metabolism of co-plasma to co-substrate [39]. Firmicutes are facultative oxygen microorganisms, and as an important component of the microbial community of MDCs, they were capable of electron transfer outside the cell [40].
According to the analysis of the genus level, Bacteroides are present in the highest proportion of $18.1 \%$, Bacteroides belongs to the order Bacteroidales, the class Bacteroidia. As mentioned above, Bacteroides can accelerate the metabolism of the co-matrix by the metabolism of organic matter and increase the activity of electrogenic bacteria. The known functional electrogenic bacteria were mainly Bacillus and Arcobacter, constituting $11.6 \%$ and $9.6 \%$ of the AMDC, respectively. Bacillus (order Bacillales and class Bacilli) are one of the most common native microorganisms in natural water [41] and have been shown to be associated with electricity generation as a typical electrogenic microbe. Arcobacter belongs to the class Epsilonproteobacteria, and the results show that Arcobacter is a dominant flora in municipal sewage and chemical bioflocculation activated sludge. Nuria et al. [42] improved the recovery of halophilic Arcobacter halophilus in seawater by using $\mathrm{NaCl}$ medium, which provided a possibility for the study of Arcobacter in the high-salt environment of MDCs.

It was found that the lack of electrogenic microorganisms in the active function of the anode chamber $(<30 \%)$ was an important factor in the poor performance of the AMDC, which was consistent with the hypothesis. To improve the effect of the AMDC, follow-up studies to
Fig. 7 Microbial communities based on the relative abundance of $16 \mathrm{~S}$ rRNA sequence of the AMDC anode biofilms in the phylum and corresponding genus levels

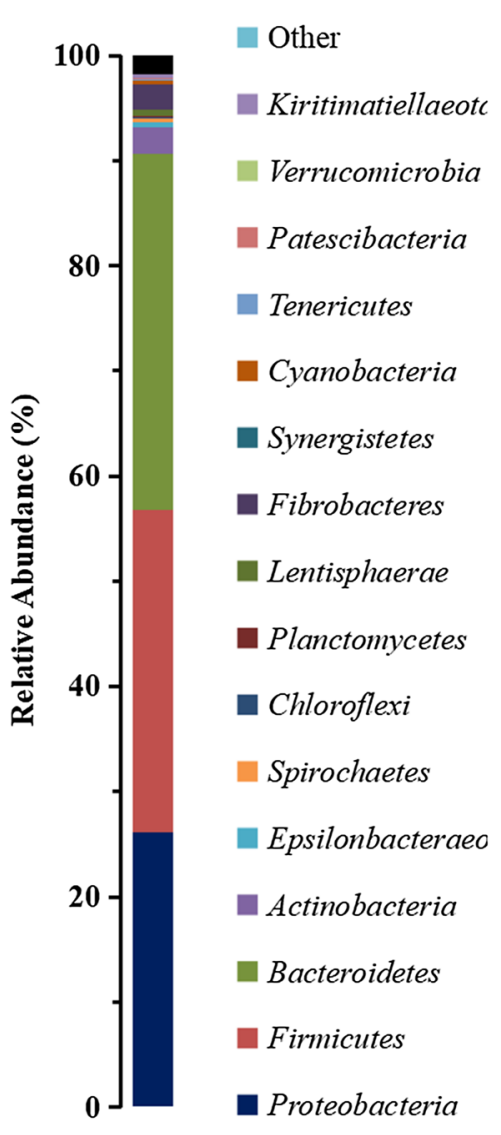

Phylum

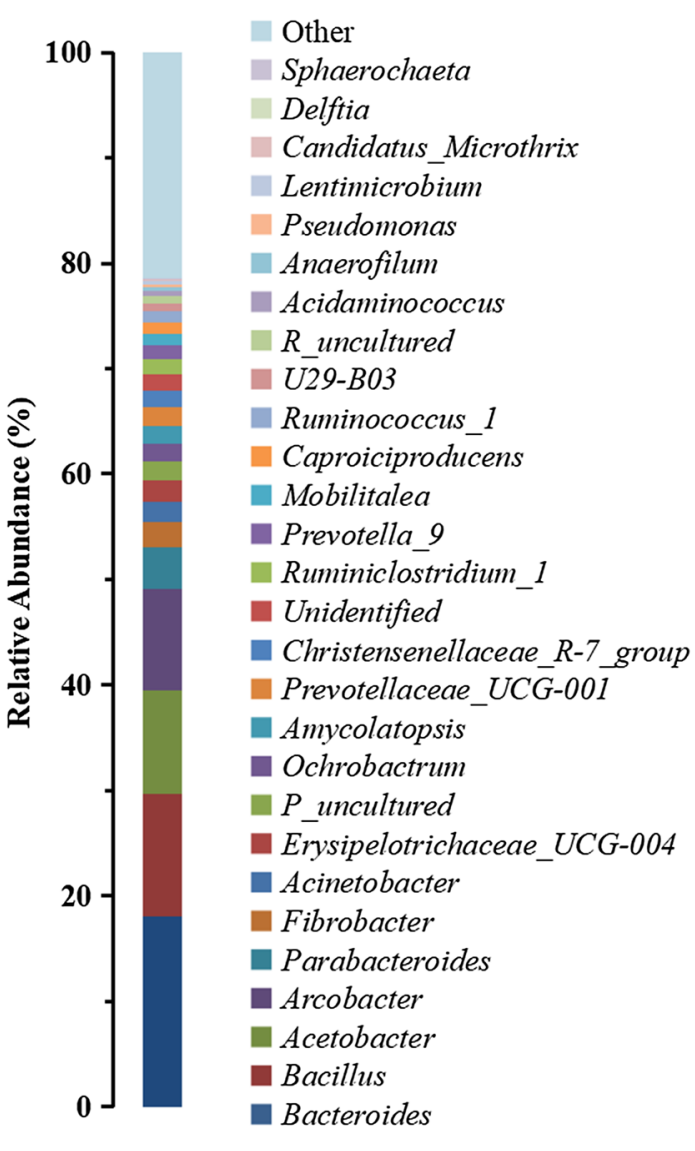

Genus 
improve the reactor and screen, isolate and purify new electrogenic microorganisms are required.

\section{Conclusion}

Microbial desalination cells constitute a promising environment-friendly desalination technology, and understanding their performance under different operating conditions and modes is helpful for their practical applications. In this study, the effect of electrode spacing on AMDC was studied.

- It was found that under identical system conditions, the AMDC with an electrode spacing of $12 \mathrm{~cm}$ exhibited the best starting effect. When the three AMDCs (with different electrode spacings) were run to the end of the cycle, a stable working state was maintained in terms of COD degradation rate and inorganic nitrogen removal. Interestingly, changes in the electrode spacing did not have any significant impact on the ability of the microorganisms to degrade organic matter and remove inorganic nitrogen. However, during the operation of the reactor, both electricity generation and desalination performance were affected by the electrode spacing. The AMDC with $12 \mathrm{~cm}$ electrode spacing showed the best performance.

- The overall output of the three AMDCs was poor. SEM images showed that the microbes were attached to the surface of the anode, and 16S rRNA microbial community structure analysis revealed that the functional electrogenic bacteria in the AMDC were Bacillus and Arcobacter. The lack of active functional electrogenic bacteria is the primary reason for the poor performance of the AMDCs.

- It has been suggested that the efficiency of these cells may be improved by upgrading the reactor and screen, isolating and purifying new electrogenic microorganisms, and applying it to the actual sewage treatment process, which would provide invaluable guidance for future research and development of this technology.

Funding The authors thank Personal Biotechnology Co., Ltd. (Shanghai, China) for conducting the Illumina MiSeq high-throughput sequencing. This study was funded by the National Natural Science Foundation of China (Grant No. 51909157), the Major Science and Technology Program for Water Pollution Control and Treatment (Grant No. 2013ZX07101014-004), and the Postdoctoral Research Foundation of China (Grant No. 2018M641983).

\section{Compliance with ethical standards}

Conflict of interest The authors declare that they have no conflict of interest.

\section{References}

1. Wang YX, Wang Y, Su XL, Qi L, Liu M (2019) Evaluation of the comprehensive carrying capacity of inter provincial water resources in China and the spatial effect. J Hydrol 575:794809. https://doi.org/10.1016/j.jhydrol.2019.05.076

2. Karthe D, Chalov S, Borchardt D (2015) Water resources and their management in central Asia in the early twenty first century: status, challenges and future prospects. Environ Earth Sci 73:487-499. https://doi.org/10.1007/s12665-014-3789-1

3. Muhammad WS, Muhammad B, Li A, Kim CN (2017) Energywater-environment nexus underpinning future desalination sustainability. Desalination 413:52-64. https://doi. org/10.1016/j.desal.2017.03.009

4. Kook S, Lee C, Nguyen TT, Lee J, Shon HK, Kim IS (2018) Serially connected forward osmosis membrane elements of pressure-assisted forward osmosis-reverse osmosis hybrid system: process performance and economic analysis. Desalination 448:1-12. https://doi.org/10.1016/j.desal.2018.09.019

5. Muhammad WS, Ng Kim Choon (2017) An improved multievaporator adsorption desalination cycle for GCC countries. Energy Technol 5(9):1663-1669. https://doi.org/10.1002/ ente. 201700061

6. Al-Othman A, Tawalbeh M, Assad ME, Alkayyali T, Eisa A (2018) Novel multi-stage flash (MSF) desalination plant driven by parabolic trough collectors and a solar pond: a simulation study in UAE. Desalination 443:237-244. https://doi.org/10.1016/j. desal.2018.06.005

7. Khalilzadeh S, Nezhad AH (2018) Utilization of waste heat of a high-capacity wind turbine in multi effect distillation desalination: energy, exergy and thermoeconomic analysis. Desalination 439:119-137. https://doi.org/10.1016/j.desal .2018.04.010

8. Muhammad WS, Muhammad B, Noreddine G, Kim CN (2017) A multi evaporator desalination system operated with thermocline energy for future sustainability. Desalination 435:268-277. https://doi.org/10.1016/j.desal.2017.04.013

9. Muhammad WS, Kyaw T, Yong-deuk K, Kim CN (2015) An experimental investigation on MEDAD hybrid desalination cycle. Appl Energy 148:273-281. https://doi.org/10.1016/j.apene rgy.2015.03.062

10. Muhammad WS, Kim CN, Kyaw T, Bidyut BS, Won GC (2014) Multi effect desalination and adsorption desalination (MEDAD): a hybrid desalination method. Appl Therm Eng 72:289-297. https ://doi.org/10.1016/j.applthermaleng.2014.03.064

11. Chen C, Jiang YL, Ye ZY, Yang Y, Hou LA (2019) Sustainably integrating desalination with solar power to overcome future freshwater scarcity in China. GEI 2(2):98-113. https://doi. org/10.1016/j.gloei.2019.07.009

12. Wu G, Hong JK, Li D, Wu ZZ (2019) Efficiency assessment of pollutants discharged in urban wastewater treatment: evidence from 68 key cities in China. J Clean Prod 233:1437-1450. https ://doi.org/10.1016/j.jclepro.2019.06.012

13. Gupta S, Pawar SB, Pandey RA (2019) Current practices and challenges in using microalgae for treatment of nutrient rich wastewater from agro-based industries. Sci Total Environ 687:11071126. https://doi.org/10.1016/j.scitotenv.2019.06.115 
14. Kim CN, Muhammad WS, Hyuk SS, Osman AH (2017) An exergy approach to efficiency evaluation of desalination. Appl Phys Lett 110(18):184101. https://doi.org/10.1063/1.4982628

15. Zamanpour MK, Kariminia HR, Vosoughi M (2017) Electricity generation, desalination and microalgae cultivation in a biocathode-microbial desalination cell. J Environ Chem Eng 5:843-848. https://doi.org/10.1016/j.jece.2016.12.045

16. Xu CL, Zhang JW, Zhang YJ (2019) Advances and problems in application of microbial desalination cells. Modern Chem Ind 8:69-72. https://doi.org/10.16606/j.cnki.issn0 253-4320.2019.08.014

17. Mostafa R, Abdelsalam E, Hisham AH (2019) Simultaneous power generation and pollutant removals using microbial desalination cell at variable operation modes. Renew Energy 143:939-949. https://doi.org/10.1016/j.renene.2019.05.068

18. Cao XX, Huang X, Liang P, Xiao K, Zhou YJ, Zhang XY, Logan BE (2009) A new method for water desalination using microbial desalination cells. Environ Sci Technol 43:7148-7152. https:// doi.org/10.1021/es901950j

19. Qu YP, Feng YJ, Wang X, Liu J, Lv JW, He WH, Logan BE (2012) Simultaneous water desalination and electricity generation in a microbial desalination cell with electrolyte recirculation for $\mathrm{pH}$ control. Bioresour Technol 106:89-94. https://doi.org/10.1016/j. biortech.2011.11.045

20. Chen C, Wang JQ, Chen SH, Lu F, Yang JP, Yang F (2013) Treatment of chromium wastewater by new microbial desalination cells. Chin J Environ Eng 7(05):1843-1848

21. Zuo KC, Cai JX, Liang S, Wu SJ, Zhang CY, Liang P, Huang X (2014) A ten liter stacked microbial desalination cell packed with mixed ion-exchange resins for secondary effluent desalination. Environ Sci Technol 48(16):9917-9924. https://doi.org/10.1021/es502 075r

22. Ma DD, Li RY, Casey F, Ren ZM, Ji M (2014) Investigation on the performance of microbial capacity desalination cell. Acta Sci Circum 34(06):1375-1380. https://doi.org/10.13671/j.hjkxx b.2014.0207

23. Mehanna M, Kiely PD, Call DF, Logan BE (2010) Microbial electrodialysis cell for simultaneous water desalination and hydrogen gas production. Environ Sci Technol 44:9578-9583. https://doi. org/10.1021/es1025646

24. Wang HM, Davidson M, ZuoY, Ren ZY (2011) Recycled tire crumb rubber anodes for sustainable power production in microbial fuel cells. J Power Sources 196(14):5863-5866. https://doi. org/10.1016/j.jpowsour.2011.01.082

25. Xie M, Xu LJ, Hu JF (2019) Effects of electrode materials on microbial fuel cells performance with treated-aging landfill leach. Acta Energ Solaris Sin 40:319-325

26. Zuo KC, Liu FB, Ren ST, Zhang XY, Liang P, Huang X (2016) A novel multi-stage microbial desalination cell for simultaneous desalination and enhanced organics and nitrogen removal from domestic wastewater. Environ Sci Water Res 2(5):832-837. https ://doi.org/10.1039/C6EW00196C

27. American Water Works Association (1998) American public health association, water pollution control federation. Standard Methods for the Examination of Water and Wastewater. American Public Health Association

28. Qu YP (2013) The configuration and performance of microbial desalination cell under continuous flow. Harbin Institute of Technology, Harbin

29. Logan BE, Hamelers B, Rozendal R, Schröder U, Keller J, Freguia S, Peter A, Verstraete W, Rabaey K (2006) Microbial fuel cells: methodology and technology. Environ Sci Technol 40(17):5181-5192. https://doi.org/10.1021/es0605016

30. Xu GF, Zheng XY, Lu YB, Liu GL, Luo HP, Li X, Zhang RD, Jin S (2019) Development of microbial community within the cathodic biofilm of single-chamber air-cathode microbial fuel cell. Sci Total Environ 665:641-648. https://doi.org/10.1016/j. scitotenv.2019.02.175

31. Luo HP, Liu GL, Zhang RD, Jin S (2009) Comparison of power generation in microbial fuel cells of two different structures. Environ Sci 30(2):621-624. https://doi.org/10.13227/j.hjkx.2009.02.048

32. Mostafa R, Abdelsalam E, Hisham AH (2019) Evaluating the performance of microbial desalination cells subjected to different operating temperatures. Desalination 462:56-66. https://doi. org/10.1016/j.desal.2019.04.008

33. Geng T (2010) Desalination of the solutions by forward osmosis. Beijing University of Chemical Technology, Beijing

34. Zuo KC, Chang JL, Liu FB, Zhang XY, Liang P, Huang X (2017) Enhanced organics removal and partial desalination of high strength industrial wastewater with a multi-stage microbial desalination cell. Desalination 423:104-110. https://doi. org/10.1016/j.desal.2017.09.018

35. Zamanpour MK, Kariminia HR, Vosoughi M (2017) Electricity generation, desalination and microalgae cultivation in a biocathode-microbial desalination cell. J Environ Chem Eng 5(1):843-848. https://doi.org/10.1016/j.jece.2016.12.045

36. Ebrahimi A, Najafpour GD, Kebria DY (2018) Performance of microbial desalination cell for salt removal and energy generation using different catholyte solutions. Desalination 432:1-9. https://doi.org/10.1016/j.desal.2018.01.002

37. Cabezas A, Pommerenke B, Boon N, Friedrich MW (2015) Geobacter, Anaeromyxobacter and Anaerolineae populations are enriched on anodes of root exudate-driven microbial fuel cells in rice field soil. Environ Microbiol Rep 7(3):489-497. https://doi. org/10.1111/1758-2229.12277

38. Hamdan HZ, Salam DA, Hari AR, Semerjian L, Saikaly P (2017) Assessment of the performance of SMFCs in the bioremediation of PAHs in contaminated marine sediments under different redox conditions and analysis of the associated microbial communities. Sci Total Environ 575:1453-1461. https://doi. org/10.1016/j.scitotenv.2016.09.232

39. Padmanabhan P, Padmanabhan S, DeRito C, Gray A, Gannon D, Snape JR, Tsai CS, Park W, Jeon C, Madsen EL (2003) Respiration of $13 \mathrm{C}$-labeled substrates added to soil in the field and subsequent 16S rRNA gene analysis of 13C-labeled soil DNA. Appl Environ Microb 69:1614-1622. https://doi.org/10.1128/ AEM.69.3.1614-1622.2003

40. Rabaey K, Rodriguez J, Blackall LL, Keller J, Gross P, Batstone D, Verstraete W, Nealson KH (2007) Microbial ecology meets electrochemistry: electricity-driven and driving communities. ISME J 1:9-18. https://doi.org/10.1038/ismej.2007.4

41. Nimje VR, Chen CY, Chen CC, Jean JS, Reddy AS, Fan CW, Pan KY, Liu HT, Chen JL (2009) Stable and high energy generation by a strain of Bacillus subtilis in a microbial fuel cell. J Power Sources 190(2):258-263. https://doi.org/10.1016/j.jpowsour.2009.01.019

42. Nuria SM, Karl BA, Furones MD, Figueras MJ (2016) Enhanced recovery of Arcobacter spp. using $\mathrm{NaCl}$ in culture media and reassessment of the traits of Arcobacter marinus and Arcobacter halophilus isolated from marine water and shellfish. Sci Total Environ 566-567:1355-1361. https://doi.org/10.1016/j.scito tenv.2016.05.197

Publisher's Note Springer Nature remains neutral with regard to jurisdictional claims in published maps and institutional affiliations. 